This is an electronic reprint of the original article. This reprint may differ from the original in pagination and typographic detail.

\author{
Author(s): Yin, Zhong; Inhester, Ludger; Veedu, Sreevidya Thekku; Quevedo, Wilson; Pietzsch, \\ Annette; Wernet, Philippe; Groenhof, Gerrit; Foehlisch, Alexander; Grubmüller, \\ Helmut; Techert, Simone
}

Title: $\quad$ Cationic and Anionic Impact on the Electronic Structure of Liquid Water

Year: $\quad 2017$

Version:

Please cite the original version:

Yin, Z., Inhester, L., Veedu, S. T., Quevedo, W., Pietzsch, A., Wernet, P., Groenhof, G., Foehlisch, A., Grubmüller, H., \& Techert, S. (2017). Cationic and Anionic Impact on the Electronic Structure of Liquid Water. Journal of Physical Chemistry Letters, 8(16), 3759-3764. https://doi.org/10.1021/acs.jpclett.7b01392

All material supplied via JYX is protected by copyright and other intellectual property rights, and duplication or sale of all or part of any of the repository collections is not permitted, except that material may be duplicated by you for your research use or educational purposes in electronic or print form. You must obtain permission for any other use. Electronic or print copies may not be offered, whether for sale or otherwise to anyone who is not an authorised user. 


\title{
Letter
}

\section{Cationic and Anionic Impact on the Electronic Structure of Liquid Water}

\author{
Zhong Yin, Ludger Inhester, Sreevidya Thekku Veedu, Wilson Quevedo, Annette Pietzsch, Philippe
}

Wernet, Gerrit Groenhof, Alexander Foehlisch, Helmut Grubmüller, and Simone Agnes Techert

J. Phys. Chem. Lett., Just Accepted Manuscript • DOI: 10.1021/acs.jpclett.7b01392 • Publication Date (Web): 25 Jul 2017

Downloaded from http://pubs.acs.org on July 31, 2017

\section{Just Accepted}

"Just Accepted" manuscripts have been peer-reviewed and accepted for publication. They are posted online prior to technical editing, formatting for publication and author proofing. The American Chemical Society provides "Just Accepted" as a free service to the research community to expedite the dissemination of scientific material as soon as possible after acceptance. "Just Accepted" manuscripts appear in full in PDF format accompanied by an HTML abstract. "Just Accepted" manuscripts have been fully peer reviewed, but should not be considered the official version of record. They are accessible to all readers and citable by the Digital Object Identifier (DOI®). "Just Accepted" is an optional service offered to authors. Therefore, the "Just Accepted" Web site may not include all articles that will be published in the journal. After a manuscript is technically edited and formatted, it will be removed from the "Just Accepted" Web site and published as an ASAP article. Note that technical editing may introduce minor changes to the manuscript text and/or graphics which could affect content, and all legal disclaimers and ethical guidelines that apply to the journal pertain. ACS cannot be held responsible for errors or consequences arising from the use of information contained in these "Just Accepted" manuscripts. 


\title{
Cationic and Anionic Impact on the Electronic
}

\section{Structure of Liquid Water}

\author{
Zhong Yin ${ }^{a, b, *,+}$, Ludger Inhester ${ }^{a, c *}{ }^{+}{ }^{+}$, Sreevidya Thekku Veedu ${ }^{a, b}$, Wilson Quevedo ${ }^{d}$, Annette \\ Pietzsch $^{d}$, Philippe Wernet ${ }^{d}$, Gerrit Groenhof ${ }^{e}$, Alexander Föhlisch ${ }^{d, f}$, Helmut Grubmüller ${ }^{b, *}$, \\ Simone Techert ${ }^{a, b, g, *}$
}

\author{
${ }^{a}$ Deutsches Elektron-Synchrotron DESY, Notkestr. 85, 22607 Hamburg, Germany \\ ${ }^{\mathrm{b}}$ Max Planck Institute for Biophysical Chemistry, Am Fassberg 11, 37077 Göttingen, Germany \\ ${ }^{\mathrm{c}}$ Center for Free-Electron Laser Science, Notkestr. 85, 22607 Hamburg, Germany \\ ${ }^{\mathrm{d}}$ Helmholtz-Zentrum Berlin GmbH, Albert-Einstein-Str. 15, 12489 Berlin, Germany \\ eUniversity of Jyväskylä, P.O. Box 35, 40014 Jyväskylä, Finland \\ ${ }^{f}$ University of Potsdam, Karl-Liebknecht-Str. 24-25, 14476 Potsdam, Germany \\ ${ }^{\mathrm{g}}$ University of Göttingen, Friedrich-Hund-Platz 1, 37077 Göttingen, Germany
}

\begin{abstract}
Hydration shells around ions are crucial for many fundamental biological and chemical processes. Their local physico-chemical properties are quite different from bulk water, and hard to probe experimentally. We address this problem by combining soft X-ray spectroscopy using a liquid jet and molecular dynamics (MD) simulations together with ab initio electronic structure calculations to elucidate the water-ion interaction in an $\mathrm{MgCl}_{2}$ solution at the molecular level. Our results reveal that salt ions mainly affect the electronic properties of water molecules in close vicinity and that the oxygen K-edge X-ray emission spectrum of water
\end{abstract}


molecules in the first solvation shell differs significantly from bulk water. Ion specific effects are identified by fingerprint features in the water X-ray emission spectra. While $\mathrm{Mg}^{2+}$ ions cause a bathochromic shift of the water lone pair orbital, the $3 \mathrm{p}$ orbital of the $\mathrm{Cl}^{-}$ions causes an additional peak in the water emission spectrum around $528 \mathrm{eV}$.

\section{TOC}

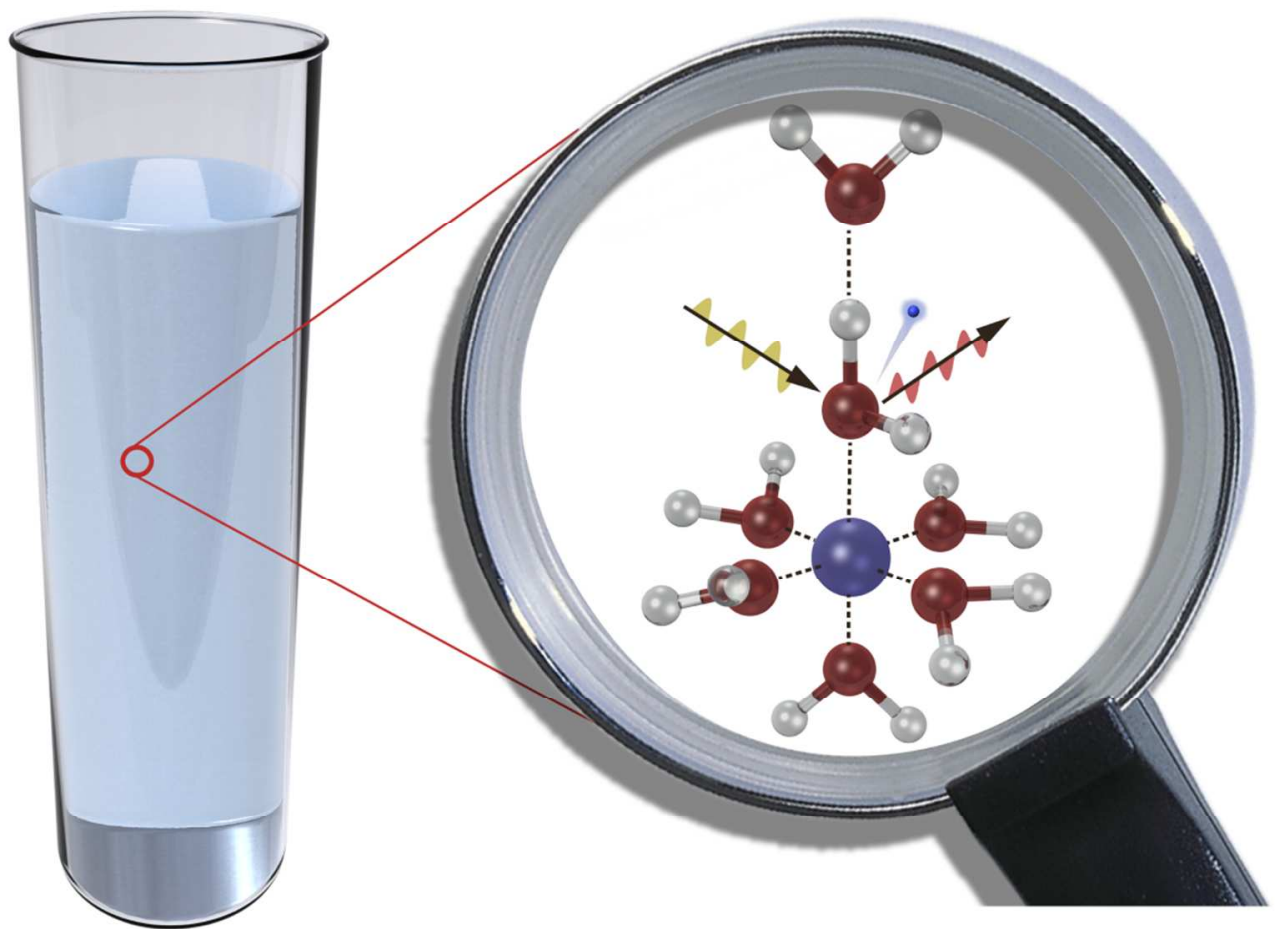

Aqueous solutions are ubiquitous in nature and play an important role for a wide range of biological, environmental and chemical processes. ${ }^{1-3}$ The solvation of water molecules around ions is of particular interest since it determines the fundamental mechanisms and dynamics of many chemical and biological systems. ${ }^{4-6}$ Ion induced changes include among others distortion of the electronic properties as well as geometrical arrangements of water molecules. A considerable number of experiments have been performed to elucidate the water-ion interaction 
and the interpretations of the data suggest sometimes a complex picture about the nature of the ion solvation. ${ }^{7-24}$ Studies from X-ray scattering, ${ }^{7}$ dielectric relaxations, ${ }^{8,9}$ infrared, ${ }^{10-13}$ NMR ${ }^{14}$ and terahertz spectroscopy ${ }^{15}$ showed that the impact on water molecules by solvated ions is mainly restricted to water molecules in close vicinity to the ion. Only for specific combinations of strongly hydrated salt ions it has been reported that the impact on the orientation of water molecules may extend beyond the first solvation shell. ${ }^{10}$ Nevertheless, neutron scattering studies revealed that the oxygen-oxygen radial distribution function is altered by $\mathrm{NaCl}$ and $\mathrm{KCl}$ solutes beyond the first solvation shell. ${ }^{16}$ The seemingly contradicting results may be due to the sensitivity of the utilized methods to different properties of the aqueous solutions. While neutron scattering probes the average of the overall structure, IR spectroscopy for example is sensitive to the dynamical properties of water.

Since the electronic properties of the water molecules are sensitive to their chemical environment, probing them may elucidate further information about the hydrogen bond (HB) structure. X-ray spectroscopy allows measuring directly the electronic properties of a system and provides direct information about the local electronic structure around a specific element in a bulk chemical environment. ${ }^{25-40}$

Previous soft X-ray absorption studies on aqueous solutions reported strong distortions of the pre-, main- and post edge of the X-ray absorption spectra on the oxygen K-edge in the vicinity of the ions. ${ }^{7,30,31,33}$ These changes have been assigned to weakening and strengthening of the hydrogen bonds in the solvation shell around the cations. ${ }^{7,30-33}$

Complementary information to X-ray absorption spectroscopy is gained from X-ray emission spectroscopy (XES). XES probes the valence electrons, which are essential for the chemical 
bonding. The X-ray emission (XE) spectrum of water shows three prominent features ${ }^{27}$ which attributes to the three outer valence orbitals of water, the lone pair orbital $1 \mathrm{~b}_{1}$ at $\sim 526 \mathrm{eV}$ and the internal bonding orbitals $3 \mathrm{a}_{1}$ at $\sim 524 \mathrm{eV}$ and $1 \mathrm{~b}_{2}$ at $\sim 521 \mathrm{eV}$. Experiments with higher energy resolution revealed additionally a splitting of the lone pair orbital contribution into two parts and further showed the sensitivity of this lone pair orbital fine structure to the hydrogen bond environment based on temperature and isotope measurements. ${ }^{35,36}$

Yet, the origin of the splitting has stirred a discussion about the nature of the fine structure. Mainly two models have been suggested to explain this effect: The fine structure arises either (1) from nuclear dynamics during the core hole lifetime ${ }^{35,41}$ or (2) from two different structural motifs. ${ }^{36}$ In model (1) the higher energy peak arises from intact water molecules and the lower energy peak from ultrafast proton transfer facilitated by intact hydrogen bonds. ${ }^{34}$ In model (2) the lower peak is from water molecules in a fully hydrogen bonded tetrahedral coordination while the higher energy peak stems from water molecules in strongly distorted HB configuration. ${ }^{36}$ Despite this controversy, there is consensus that the XE spectrum of water on the oxygen $\mathrm{K}$-edge is a fingerprint of the hydrogen bond network. ${ }^{27,35,36}$

Recently, several soft XES experiments have reported that the electronic properties of water is altered by the presence of salt ions only at high salt concentrations. ${ }^{28,37-40}$ However, the dominating change that is observed is an intensity decrease of the lower energy part of the split lone pair orbital peak in dependence of the concentration and the type of salt ions, which consisted mainly of $\mathrm{Cl}^{-}$as anion and various cations $\left(\mathrm{NH}_{4}^{+}, \mathrm{Li}^{+}, \mathrm{K}^{+}, \mathrm{Na}^{+}, \mathrm{Mg}^{2+} \& \mathrm{Ca}^{2+}\right)$. These changes were assigned to the distortion of the hydrogen bond network. ${ }^{28,37-40}$ The modification in the electronic properties were relatively small such that even at the highest concentration for monovalent $(7 \mathrm{M})$ and divalent $\left(4 \mathrm{M}\right.$ for $\left.\mathrm{CaCl}_{2}\right)$ salt ions the splitting was still observed. 
The changes were assigned to the impact of the cations by comparing changing cations with the same $\mathrm{Cl}^{-}$concentration ${ }^{28,40}$

Jeyachandran et $a l .{ }^{37}$ introduced a three component fit based on water model (1) and assigned one component to water molecules in the first solvation shell. Recently, the same authors also studied $\mathrm{KBr}, \mathrm{KCl}, \mathrm{MgCl}_{2}$ and $\mathrm{CaCl}_{2}$ at various concentrations and observed in highly concentrated $(>3 \mathrm{M})$ solution a stronger increase of the extracted component for the $\mathrm{Br}^{-}$anion than the $\mathrm{Cl}^{-}$anion. ${ }^{39}$ Additionally, this component of $\mathrm{MgCl}_{2}$ and $\mathrm{CaCl}_{2}$ solutions was twice as strong as for monovalent salt solutions. Therefore, they concluded that this component represents the first hydration shell around anions. However, because of the higher charge of divalent cations compared to the monovalent cations, it is also conceivable that the increase of the additional component is due to the contribution by water molecules in the first solvation shell of the divalent cations.

The aim of the present study is therefore to elucidate the nature of ion-water interactions and its effect on the electronic properties of water using a combined study of soft X-ray spectroscopy with $a b$ initio electronic structure calculation on aqueous solutions. We address the question how salt ions change the electronic properties of liquid water and reveal the origin of the previously observed additional peak at $\sim 528 \mathrm{eV}$. To that end we investigate the impact of salt ions in highly concentrated $\mathrm{MgCl}_{2}$ solutions. Compared to monovalent cations like sodium or potassium, magnesium is divalent and one expects a stronger interaction with the surrounding water molecules. Also, because $\mathrm{Mg}^{2+}$ has a markedly shorter ion-water distance than $\mathrm{Ca}^{2+} .{ }^{42}$ 
Figure 1 shows the XE spectra of $4 \mathrm{M} \mathrm{MgCl}_{2}$ solution compared to pure water. The excitation energy was set at non-resonant energy above the post edge according to the XAS results, see SI. They have been area normalised for an accurate comparison of relative intensities.

For pure water (blue), three regions can be distinguished as described in the introduction. The lone pair peak shows a double peak structure in the pure water spectrum in agreement with previous results. ${ }^{35,36}$ For the $4 \mathrm{M}$ solution the intensity of the bonding orbitals $1 \mathrm{~b}_{2}$ and $3 \mathrm{a}_{1}$ in $\mathrm{MgCl}_{2}$ solution is more pronounced.

In contrast to the splitting in the lone pair region of pure water, for the $4 \mathrm{M}$ salt solution (red) only one peak is seen. Further, this $1 b_{1}$ peak is shifted to lower energies and to a position between the peaks of the lone pair orbital for the pure water spectrum, while the position of the other contributions is rather similar.

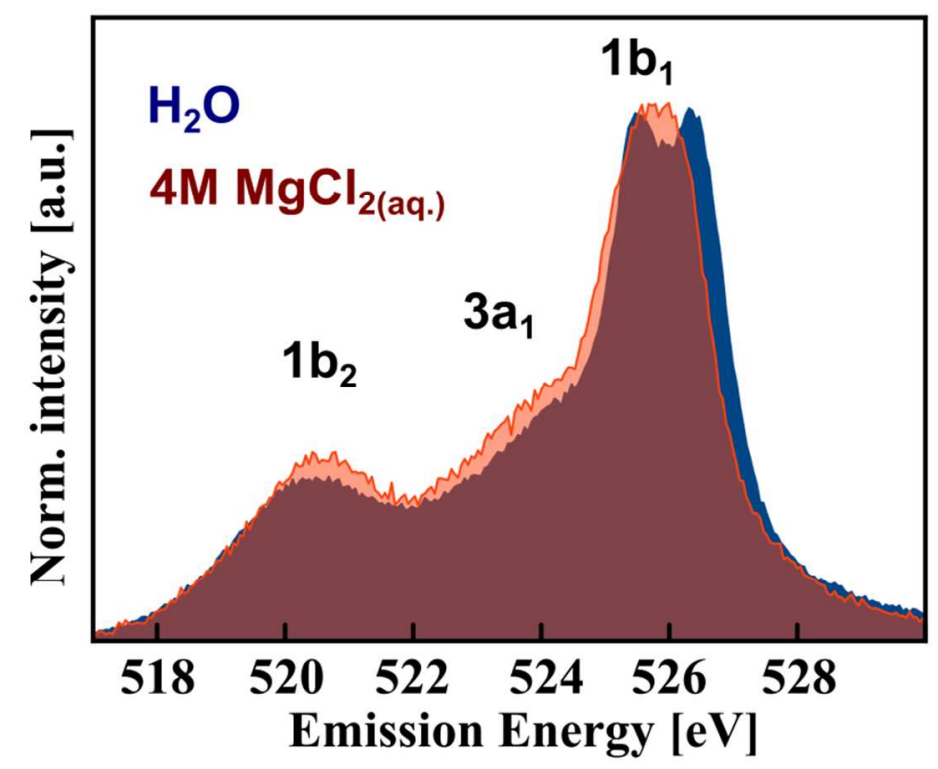

Figure 1: The X-ray emission spectra of pure water in comparison with $4 \mathrm{M} \mathrm{MgCl}_{2(\mathrm{aq})}$ solutions on the oxygen K-edge are shown. 
In previous works no strong effects on the water's valence electronic configuration has been observed for a $2 \mathrm{M} \mathrm{MgCl} 2$ and for a $\mathrm{CaCl}_{2}$ solution with concentration up to $4 \mathrm{M},{ }^{39}$ which contains the same number of $\mathrm{Cl}^{-}$anions as in our $4 \mathrm{M} \mathrm{MgCl}_{2}$ solution. The differences to these previous studies are most likely due to the lower concentration $(2 \mathrm{M}$ vs $4 \mathrm{M})$ and the different cation, since $\mathrm{Mg}^{2+}$ has a much tighter hydration shell than the $\mathrm{Ca}^{2+}$ cation. ${ }^{42}$

Given fact that former studies (experimental and theoretical) show a negligible effect of $\mathrm{Cl}^{-}$ions on the electronic structure of water, even for very high concentrations, ${ }^{7,24,28,30,32,33,40}$ we assume the number of water molecules in direct contact with $\mathrm{Mg}^{2+}$ ions can explain most of the salt-induced spectral changes in our $4 \mathrm{M}$ solution. Accordingly, we expect the major effects of salt on the electronic properties can be understood to first approximation from the electronic configuration of the water molecules in the first solvation shell around $\mathrm{Mg}^{2+}$ ion. Based on this additional idea, we consider the solution spectrum of the valence electronic states of water $\boldsymbol{f}(\boldsymbol{E})$ to be a linear combination of the spectra arising from water molecules in the first solvation shell around $\mathrm{Mg}^{2+}, \boldsymbol{f}_{\boldsymbol{M g}}(\boldsymbol{E})$, and those arising from water molecules not in direct contact with $\mathrm{Mg}^{2+}$, contributing with the spectrum of bulk water, $\boldsymbol{f}_{\mathbf{b u l k}}(\boldsymbol{E})$. Referring to the above arguments, we assume that the $\mathrm{XE}$ spectrum of water molecules close to $\mathrm{Cl}^{-}$anions is similar as the $\mathrm{XE}$ spectrum of bulk water, such that the $4 \mathrm{M} \mathrm{MgCl}_{2}$ spectrum is given by $\boldsymbol{f}(\boldsymbol{E})=\boldsymbol{\alpha} \boldsymbol{f}_{\boldsymbol{M g}}(\boldsymbol{E})+(\mathbf{1}-$ $\boldsymbol{\alpha}) \boldsymbol{f}_{\text {bulk }}(E)$.

From the measured spectrum $f(E)$ we thus obtain a good approximation for the isolated spectrum of water molecules in the first solvation shell of $\mathrm{Mg}^{2+}, \boldsymbol{f}_{\boldsymbol{M g}}(\boldsymbol{E})=\frac{\mathbf{1}}{\boldsymbol{\alpha}}(\boldsymbol{f}(\boldsymbol{E})-(\mathbf{1}-$ $\boldsymbol{\alpha}) \boldsymbol{f}_{\text {bulk }}(\boldsymbol{E})$ ), by taking the weighted difference of measured bulk water and solution spectra. The coefficient $\alpha$ is determined from the relative number of water molecules in the first solvation 
shell of $\mathrm{Mg}^{2+}$. At $4 \mathrm{M}$ concentration, there are 13 water molecules per $\mathrm{MgCl}_{2}$ salt moiety. Even at this high concentration direct ion pairing is unlikely ${ }^{43}$, but there might be a relevant quantity of water molecules in direct contact with both ions. Since we ignore for the moment the impact of $\mathrm{Cl}^{-}$ions altogether, we assume them to contribute to the spectrum like the water molecules in direct contact with an $\mathrm{Mg}^{2+}$ ion only. Considering the coordination number for $\mathrm{Mg}^{2+}$, which is $6,{ }^{44}$ results in $\alpha=6 / 13 \approx 0.46$. Figure 2 shows the resulting spectrum, now dominated by the signal from water molecules in the first shell around $\mathrm{Mg}^{2+}$. The difference spectrum shows two pronounced peaks $1 b_{1}$ and $1 b_{2}$ and a broad peak between them corresponding to the three outer valence orbital contributions. No clear splitting is observed in the lone pair region. Further, an additional shoulder appears at $\sim 528 \mathrm{eV}$. This difference spectrum looks very similar to the new component extracted from the water model (1) reported in Ref [37].

To explain the energy shifts and the additional shoulder $\sim 528 \mathrm{eV}$, we compare these experimental results to $a b$ initio electronic structure calculations on water clusters sampled from MD simulations with and without ions. To address the question to which distances the electronic properties of water are influenced by the ions, we calculate spectra for a very dilute solutions and inspect the spectra stemming from the different solvation shells around the ions. The comparison with the experimental difference spectrum at high salt concentration requires the additional assumption that the structure of the $\mathrm{Mg}^{2+}$ solvation shells is mainly unaffected by the $\mathrm{MgCl}_{2}$ concentration. 


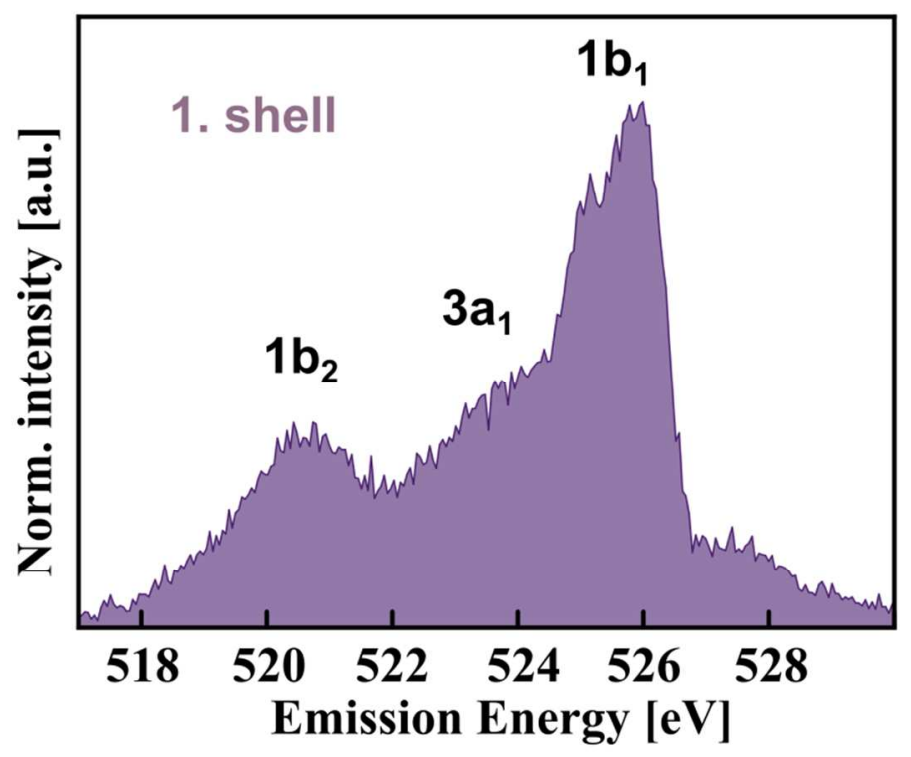

Figure 2: The difference spectrum between $4 \mathrm{M} \mathrm{MgCl}_{2}$ and pure water is displayed. The difference represents the first hydration shell of water molecules around $\mathrm{Mg}^{2+}$.

In Figure 3 top tier (I \& II) we compare the first solvation shell spectrum with pure water. A bathochromic shift $(\sim 0.4 \mathrm{eV})$ in the spectrum for the $1 \mathrm{~b}_{1}$ orbital can be observed.

Figure 3 lower tier (III, IV, V \& VI) shows the calculated fluorescence spectrum after core ionization for pure water (III) and for water in the first (VI) and second (V) solvation of $\mathrm{Mg}^{2+}$ and first (IV) shell of $\mathrm{Cl}^{-}$. These are compared to the experimental results of pure water (I) and the measured difference spectrum corresponding to the first (II) shell of $\mathrm{Mg}^{2+}$. 


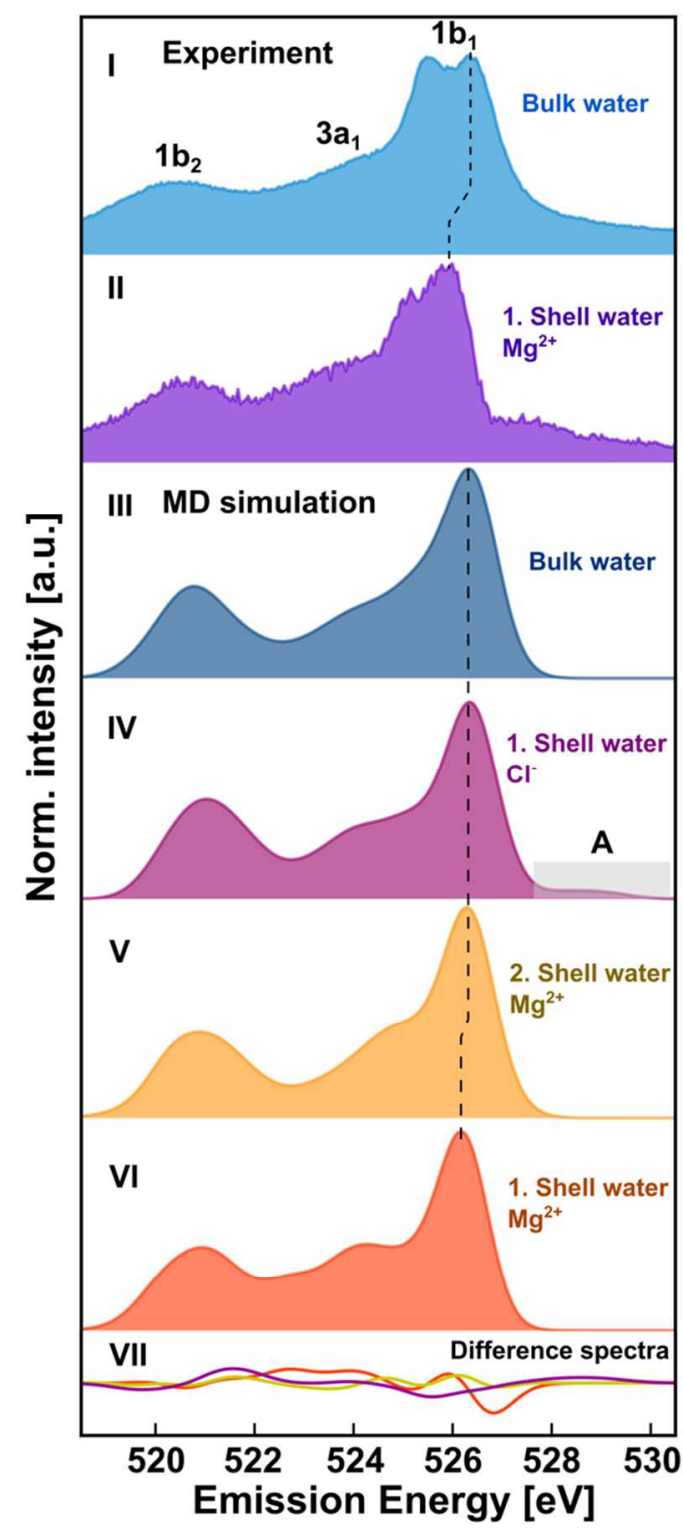

Figure 3: Ab initio spectra of pure water clusters compared with the first and second solvation shell of water around $\mathrm{Mg}^{2+}$ and first shell around $\mathrm{Cl}^{-}$ions with experimental results of pure water and the first around $\mathrm{Mg}^{2+}$ ion. The dashed line is a guide to the eye to illustrate the shift of the $1 b_{1}$ peak position. Tier VII shows color coded the difference spectra of the solvation shells to bulk water for the theoretical results.

As can be seen, the calculation reproduces the different $1 b_{1}, 3 a_{1}, 1 b_{2}$ orbital contribution that are seen in the measured spectrum. The split peak of the $1 b_{1}$ part is not reproduced by the calculation. As discussed before, this feature might stem from proton dynamics during the core hole lifetime ${ }^{41}$ that are not included in our calculation. Alternatively, the fine structure might 
stem from two different structural motifs in the local hydrogen bond structure. However, in our calculation these structural motifs may not be correctly reproduced by the utilized force field approach. Therefore, we cannot give a satisfactory answer on the origin of the peak splitting. Apart from this discrepancy, we think that the calculation shows overall good agreement with the measured spectrum, that allows us to understand the qualitative salt-induced changes.

For the fluorescence spectrum of the salt solution, we classify the calculated fluorescence spectrum for water molecules ionized in the first and second solvation shell of $\mathrm{Mg}^{2+}$ and first solvation shell around $\mathrm{Cl}^{-}$, respectively. Thus, we can identify the impact of the ions on the fluorescence spectrum as a function of distance to the different ions. As can be seen, for all the different water molecule classes, the $1 b_{2}$ and $3 a_{1}$ orbital contributions are rather unaffected. For the first hydration shell (IV) around $\mathrm{Cl}^{-}$and the second solvation shell (V) around $\mathrm{Mg}^{2+}$ the calculated spectrum is very similar to the calculated pure water spectrum, whereas the first solvation shell (VI) around the $\mathrm{Mg}^{2+}$ ions, the $1 \mathrm{~b}_{1}$ orbital contribution is red-shifted, which is also mirrored in the difference spectra in tier VII. In the difference spectra are noticeable changes in the second solvation shell around the $\mathrm{Mg}^{2+}$ observed. However, they are much weaker compared to the first solvation shell modifications. The red shift can be explained by the $\mathrm{Mg}^{2+}$ induced polarization changes of water molecules. The lone pair orbital points towards the cation such that the electrostatic interaction between the water molecules and the $\mathrm{Mg}^{2+}$ cation lowers the energy of the lone pair orbital and hence lowers the emitted X-ray for a re-occupation of the core hole from this orbital.

For the fluorescence spectrum of the water molecules in proximity to $\mathrm{Cl}^{-}$ions we see an additional shoulder above $528 \mathrm{eV}$, see tier IV A in Figure 3. This additional contribution was reported in a previous calculation ${ }^{45}$ and has also been observed before in the three component 
spectra fit of the aqueous solution spectrum based on the water model (1). ${ }^{37}$ Closer inspection of the electronic structure reveals that this fluorescence signal stems from molecular orbital representing the $3 \mathrm{p}$ shell of $\mathrm{Cl}^{-}$with slight contribution in the valence orbitals of the ionized water molecules. We can therefore assign it to a refilling of the oxygen core vacancy from the $\mathrm{Cl}^{-}$ anion.

Taken altogether, our calculations show that, indeed, $\mathrm{Mg}^{2+}$ affects mainly the electronic properties of water molecules in close proximity. Whereas the water molecules close to $\mathrm{Mg}^{2+}$ ions have a bathochromic $1 b_{1}$ shift, water molecules close to $\mathrm{Cl}^{-}$show more or less an undistorted pure water XE spectrum augmented by an additional shoulder at $528 \mathrm{eV}$. Therefore, the additional shoulder in the experimental difference spectrum at $\sim 528 \mathrm{eV}$ which we in Figure 3 tentatively assigned to the first solvation shell of $\mathrm{Mg}^{2+}$ must be attributed to the water molecules in the vicinity of $\mathrm{Cl}^{-}$anions.

In the comparison, we assumed that the solvation structure around $\mathrm{Mg}^{2+}$ is independent of the salt concentration. However, for the high salt concentration investigated here, it is conceivable that water molecules are in direct contact with an $\mathrm{Mg}^{2+}$ and $\mathrm{Cl}^{-}$ion. Considering that the overall ion impact on the XE spectra is rather small we speculate that the ion's impact is additive and in this case a water molecule may show both ion induced features, for further discussion see SI.

In experimental XE studies, noticeable distortion in the electronic properties of water is only observed at high salt concentration. ${ }^{28,37-39}$ Theoretical results show significant changes in the electronic properties of water molecules in proximity of the ions. For water molecules in the second solvation shell of the ion and beyond, the electronic properties of water show negligible distortions compared to bulk water. Based on these facts, we conclude that ions mainly influence the electronic properties of water molecules in close vicinity. Soft XES is therefore particularly 
sensitive to the local environment of the ion and less sensitive to the geometrical arrangement of water molecules in the bulk far from the ion.

In summary, we compared the XE spectrum of $4 \mathrm{M} \mathrm{MgCl}_{2}$ solution with that of pure water, and revealed significant differences in the electronic properties of water. Results from ab initio electronic structure calculations agree with our experimental findings, except for the fine structure of the $1 b_{1}$ peak region which is likely due to the lack of explicit core-hole excited-state dynamics in the spectra calculations. ${ }^{41}$ Because of this agreement, the simulation results serve to explain the observed differences in terms of a microscopic model. Accordingly, it is mainly the water molecules in the immediate vicinity of the salt ions whose electronic properties are markedly affected thereby defining the sensitivity of our probe.

Our results show that salt ions have indeed a significant impact on the electronic properties and that cation and anion have ion specific influence on the electronic states of water, such that anionic and cationic effects leave different fingerprints on the XE spectra. The interaction of the first solvation shell water molecules with $\mathrm{Cl}^{-}$anions leads to an additional signal at $\sim 528 \mathrm{eV}$. In the first solvation shell around $\mathrm{Mg}^{2+}$ ion the lone pair orbital of water is bathochromatically shifted. Furthermore, the origin of the specific ions effects can be explained by $\mathrm{Mg}^{2+}$ cation induced polarization changes in water and contributions of the $3 p$ shell of $\mathrm{Cl}^{-}$anions.

We think that the combination of soft X-ray spectroscopy with MD sampled ab initio electronic structure calculations developed and demonstrated here, can serve to probe molecular interaction in a broad range of different condensed matter systems, including highly complex biomolecular structures. 


\section{Experimental and Simulation Method}

The experiments were performed at the beamline U41 of BESSY II synchrotron at the Helmholtz Zentrum Berlin using the FlexRIXS endstation ${ }^{46}$ and at P04 of PETRA III using the ChemRIXS $^{47}$ setup. For excitation, a monochromatic soft X-ray beam has been utilized. The $\mathrm{MgCl}_{2}$ solution was prepared from $>99.0 \% \mathrm{MgCl}_{2} \cdot 6 \mathrm{H}_{2} \mathrm{O}$ (Magnesium Chloride Hexahydrate) from Sigma - Aldrich at least 24 hours prior to the experiment. The non-resonant excitation energies have been selected from the X-ray absorption (XA) spectra of water and aqueous solutions recorded in the total fluorescence yield mode, see SI. XA and XE spectra of pure water were recorded periodically to confirm the stability of the setup, see SI. The resolution of the spectrometer was $\sim 0.4 \mathrm{eV}$ at $530 \mathrm{eV}$ (oxygen K-edge). The elastic peaks have been used for energy calibration.

To perform ab-initio calculation of the XE spectrum of liquids we have sampled molecular geometries from molecular dynamics calculations. The MD calculations have been conducted using the gromacs 4.5.5 program $^{48}$ employing the Particle-Mesh-Ewald method (r_cutoff $=0.85$ $\mathrm{nm}$, fourier spacing $=0.12 \mathrm{~nm})$ with Noose-Hoover temperature coupling $(\tau=0.1 \mathrm{ps})$ and Parinello-Rahman pressure coupling ( $\tau=4.0 \mathrm{ps}$ ). The flexible Fergusson force-field ${ }^{49}$ has been used with a time-step of 0.5 fs. For pure water, we have performed a 100ps-MD simulation of a box containing 1410 water molecule at a temperature of $300 \mathrm{~K}$ and a pressure of $10^{5} \mathrm{~Pa}$.

Since we expect the impact of the ions to be restricted to the first solvation shells, we have performed simulations at low salt concentration. The same setup as before has been used to conduct 100ps-MD simulations for a box containing 1426 water molecules with a single $\mathrm{Mg}^{2+}$ ion and two $\mathrm{Cl}^{-}$ions. The interaction of the ions with the water molecules was described using the gromos $45 \mathrm{a} 3$ force field. ${ }^{50}$ For the discussion of the validity utilizing this force field approach see SI. From these MD simulations, water molecules have been randomly picked at different 
snapshots to sample the local environment around the ionized water molecule. For the calculations of the XE spectrum, clusters around the ionized water molecule have been constructed that include neighboring water molecules (oxygen-oxygen distance smaller than 3.5 $\AA$ ) and neighboring ions (oxygen-ion distance smaller than $4 \AA$ ). These clusters have been considered explicitly in the electronic structure calculations while molecules and ions within a sphere of $10 \AA$ around the ionized oxygen were included as point charges in the electronic structure calculations via electrostatic embedding.

For each of these molecule clusters restricted Hartree Fock orbitals with localized core orbitals have been calculated employing a $6-31 \mathrm{G}(\mathrm{d})^{51}$ basis set using the psi3 electronic structure package. ${ }^{52}$ Using this orbital set the initial core ionized electronic state $\Psi_{i}$ has been described using a configuration interaction (CI) calculation involving all configurations with single excitations from the water valence orbitals into virtual orbitals, while the core hole orbital on the core ionized oxygen atom has been kept singly occupied. The final valence-ionized state has been described using a CI calculation involving all possible valence orbital vacancies and reoccupied core orbital. From these CI solutions the transition rate for fluorescence has been evaluated from

$$
I_{0}=\frac{4}{3} \alpha^{3} \omega^{3} \sum_{j=x, y, z}\left|\left\langle\Psi_{i}\left|d_{j}\right| \Psi_{f}\right\rangle\right|^{2}
$$

where $d$ is the dipole moment operator and $\omega=E_{i}-E_{f}$, with $E_{f}$ and $E_{i}$ being the final and initial state energies from the CI solutions, respectively. Finally, the obtained fluorescence line spectrum has been convoluted with a Gaussian function of $1 \mathrm{eV}$ FWHM to account for vibrational broadening effects and accumulated for the various water clusters. To distinguish the different chemical effects, the XE spectra have been assembled for water molecules in different chemical environments. For water molecules in the first solvation shell around $\mathrm{Mg}^{2+}, \mathrm{Cl}^{-}$, and for 
water molecules in the second solvation shell of $\mathrm{Mg}^{2+}$, as well as for water molecules stemming from the neat water simulation, the XE spectrum has been assembled from $\sim 80$ different water clusters, respectively.

All calculated spectra have been shifted by $0.2 \mathrm{eV}$ to lower energies for a better comparison with the experimental spectra.

\section{AUTHOR INFORMATION \\ Corresponding Author \\ *zhong.yin@desy.de (Zhong Yin) \\ *ludger.inhester@desy.de (Ludger Inhester) \\ *hgrubmu@gwdg.de (Helmut Grubmüller) \\ *simone.techert@,desy.de (Simone Techert)}

${ }^{+}$Z. Yin and L. Inhester contributed equally to this work.

\section{Funding Sources}

This works was supported by SFB755 "Nanoscale Photonic Imaging” and SFB 1073 “Atomic Scale Control of Energy Conversion" project C02 of the German Science Foundation (DFG), the Max Planck Institute for Biophysical Chemistry, Deutsches Elektronen-Synchrotron and the Helmholtz Virtual Institute "Dynamic Pathways in Multidimensional Landscapes". S.T. is grateful to the Funds of the Chemical Industry. G.G. acknowledges financial support from the Academy of Finland (Grant 258806). 


\section{ACKNOWLEDGMENT}

We thank the staff of U41 at HZB and P04 at PETRA III for their support.

\section{ASSOCIATED CONTENT}

Additional experimental and theoretical data as mentioned in the text.

\section{ABBREVIATIONS}

XES, XAS, HB

\section{REFERENCES}

(1) Bakker, H. J. Structural Dynamics of Aqueous Salt Solutions. Chem. Rev. 2008, $108,1456-1473$.

(2) Hayes, R.; Warr, G. G.; Atkin, R. Structure and Nanostructure in Ionic Liquids. Chem. Rev. 2015, 115, 6357-6426.

(3) Jungwirth, P.; Tobias, D. J. Specific Ion Effects at the Air/water Interface. Chem. Rev. 2006, 106, 1259-1281.

(4) Lo Nostro, P.; Ninham, B. W. Hofmeister Phenomena: An Update on Ion Specificity in Biology. Chem. Rev. 2012, 112, 2286-2322.

(5) Ebbinghaus, S.; Kim, S. J.; Heyden, M.; Yu, X.; Heugen, U.; Gruebele, M.; Leitner, D. M.; Havenith, M. An Extended Dynamical Hydration Shell around Proteins. Proc. Natl. Acad. Sci. U. S. A. 2007, 104, 20749-20752.

(6) Alexander, R. T.; Hoenderop, J. G.; Bindels, R. J. Molecular Determinants of Magnesium Homeostasis: Insights from Human Disease. J. Am. Soc. Nephrol. 2008, 19, $1451-1458$.

(7) Waluyo, I.; Huang, C.; Nordlund, D.; Bergmann, U.; Weiss, T. M.; Pettersson, L. G. M.; Nilsson, A. The Structure of Water in the Hydration Shell of Cations from X-Ray Raman and Small Angle X-Ray Scattering Measurements. J. Chem. Phys. 2011, 134, $64513,1-10$. 
Wachter, W.; Fernandez, S.; Buchner, R.; Hefter, G. Ion Association and Hydration in Aqueous Solutions of LiCl and Li2SO4 by Dielectric Spectroscopy. J. Phys. Chem. B 2007, 111, 9010-9017.

Rahman, H. M. A.; Hefter, G.; Buchner, R. Hydration of Formate and Acetate Ions by Dielectric Relaxation Spectroscopy. J. Phys. Chem. B 2012, 116, 314-323.

(10) Tielrooij, K. J.; Garcia-Araez, N.; Bonn, M.; Bakker, H. J. Cooperativity in Ion Hydration. Science 2010, 328, 1006-1009.

(11) Omta, A. W.; Kropman, M. F.; Woutersen, S.; Bakker, H. J. Negligible Effect of Ions on the Hydrogen-Bond Structure in Liquid Water. Science (80-. ). 2003, 301, 347349.

Kropman, M. F.; Bakker, H. J. Vibrational Relaxation of Liquid Water in Ionic Solvation Shells. Chem. Phys. Lett. 2003, 370, 741-746.

(13) Park, S.; Odelius, M.; Gaffney, K. J. Ultrafast Dynamics of Hydrogen Bond Exchange in Aqueous Ionic Solutions. J. Phys. Chem. B 2009, 113, 7825-7835.

(14) Struis, R. P. W. L.; Bleijser, J. de; Leyte, J. C. Mg-25(2+) and Cl-35Quadrupolar Relaxation in Aqueous Mgc12 Solutions At 25-Degrees-C .2. Relaxation At Finite Mgcl2 Concentrations. J Phys Chem 1989, 93, 7943-7952.

(15) Funkner, S.; Niehues, G.; Schmidt, D. A.; Heyden, M.; Schwaab, G.; Callahan, K. M.; Tobias, D. J.; Havenith, M. Watching the Low-Frequency Motions in Aqueous Salt Solutions: The Terahertz Vibrational Signatures of Hydrated Ions. J. Am. Chem. Soc. 2012, 134, 1030-1035.

(16) Mancinelli, R.; Botti, A.; Bruni, F.; Ricci, M. A.; Soper, A. K. Hydration of Sodium, Potassium, and Chloride Ions in Solution and the Concept of Structure Maker/breaker. J. Phys. Chem. B 2007, 111, 13570-13577.

(17) Winter, B.; Aziz, E. F.; Ottosson, N.; Faubel, M.; Kosugi, N.; Hertel, I. V. Electron Dynamics in Charge-Transfer-to-Solvent States of Aqueous Chloride Revealed by Cl- 2p Resonant Auger-Electron Spectroscopy. J. Am. Chem. Soc. 2008, 130, 71307138.

Jungwirth, P.; Tobias, D. J. Chloride Anion on Aqueous Clusters, at the AirWater Interface, and in Liquid Water: Solvent Effects on Cl-Polarizability. J. Phys. Chem. A 2002, 106, 379-383. 
Xie, W. J.; Gao, Y. Q. A Simple Theory for the Hofmeister Series. J. Phys. Chem. Lett. 2013, 4, 4247-4252.

Zhang, R.; Zhuang, W. Cation Effect in the Ionic Solution Optical Kerr Effect Measurements: A Simulation Study. J. Chem. Phys. 2014, 140, 54507.

(21) Zhang, Y.; Cremer, P. S. The Inverse and Direct Hofmeister Series for Lysozyme. Proc. Natl. Acad. Sci. U. S. A. 2009, 106, 15249-15253.

(22) Marcus, Y. The Effect of Complex Anions on the Structure of Water. J. Solution Chem. 2015, 44, 2258-2265.

(23) Chen, Y.; Okur, H. I.; Gomopoulos, N.; Macias-Romero, C.; Cremer, P. S.; Petersen, P. B.; Tocci, G.; Wilkins, D. M.; Liang, C.; Ceriotti, M.; et al. SI - Electrolytes Induce Long-Range Orientational Order and Free Energy Changes in the H-Bond Network of Bulk Water. Sci. Adv. 2016, 2, e1501891-e1501891.

(24) Gaiduk, A. P.; Galli, G. Local and Global Effects of Dissolved Sodium Chloride on the Structure of Water. J. Phys. Chem. Lett. 2017, 8, 1496-1502.

(25) de Groot, F. M. F. Multiplet Effects in X-Ray Spectroscopy. Coord. Chem. Rev. 2005, 249, 31-63.

(26) J. Stöhr, NEXAFS Spectroscopy (Springer, Berlin, 1991).

(27) Guo, J.-H.; Luo, Y.; Augustsson, a.; Rubensson, J.-E.; Såthe, C.; Ågren, H.; Siegbahn, H.; Nordgren, J. X-Ray Emission Spectroscopy of Hydrogen Bonding and Electronic Structure of Liquid Water. Phys. Rev. Lett. 2002, 89, 1-4.

(28) Yin, Z.; Rajkovic, I.; Kubicek, K.; Quevedo, W.; Pietzsch, A.; Wernet, P.; Föhlisch, A.; Techert, S. Probing the Hofmeister Effect with Ultrafast Core-Hole Spectroscopy. J. Phys. Chem. B 2014, 118, 9398-9403.

(29) Wernet, P.; Nordlund, D.; Bergmann, U.; Cavalleri, M.; Odelius, M.; Ogasawara, H.; Näslund, L. A.; Hirsch, T. K.; Ojamäe, L.; Glatzel, P.; et al. The Structure of the First Coordination Shell in Liquid Water. Science 2004, 304, 995-999.

(30) Näslund, L.-A.; Edwards, D. C.; Wernet, P.; Bergmann, U.; Ogasawara, H.; Pettersson, L. G. M.; Myneni, S.; Nilsson, A. X-Ray Absorption Spectroscopy Study of the Hydrogen Bond Network in the Bulk Water of Aqueous Solutions. J. Phys. Chem. A 2005, 109, 5995-6002. 
(31) Cappa, C. D.; Smith, J. D.; Wilson, K. R.; Messer, B. M.; Gilles, M. K.; Cohen, R. C.; Saykally, R. J. Effects of Alkali Metal Halide Salts on the Hydrogen Bond Network of Liquid Water. J. Phys. Chem. B 2005, 109, 7046-7052.

Kulik, H. J.; Marzari, N.; Correa, A. A.; Prendergast, D.; Schwegler, E.; Galli, G. Local Effects in the X-Ray Absorption Spectrum of Salt Water. J. Phys. Chem. B 2010, 114, 9594-9601.

Waluyo, I.; Nordlund, D.; Bergmann, U.; Schlesinger, D.; Pettersson, L. G. M.; Nilsson, A. A Different View of Structure-Making and Structure-Breaking in Alkali Halide Aqueous Solutions through X-Ray Absorption Spectroscopy. J. Chem. Phys. 2014, 140, 244506,1-11.

Aziz, E. F.; Ottosson, N.; Eisebittt, S.; Eberhardt, W.; Winter, B. Cation-Specific Interactions with Carboxylate in Amino Acid and Acetate Aqueous: X-Ray Absorption and Ab Initio Calculations. J. Phys. Chem. B 2008, 112, 12567-12570.

Fuchs, O.; Zharnikov, M.; Weinhardt, L.; Blum, M.; Weigand, M.; Zubavichus, Y.; Bär, M.; Maier, F.; Denlinger, J.; Heske, C.; et al. Isotope and Temperature Effects in Liquid Water Probed by X-Ray Absorption and Resonant X-Ray Emission Spectroscopy. Phys. Rev. Lett. 2008, 100, 027801,1-4.

(36) Tokushima, T.; Harada, Y.; Takahashi, O.; Senba, Y.; Ohashi, H.; Pettersson, L. G. M.; Nilsson, A.; Shin, S. High Resolution X-Ray Emission Spectroscopy of Liquid Water: The Observation of Two Structural Motifs. Chem. Phys. Lett. 2008, 460, 387400.

Jeyachandran, Y. L.; Meyer, F.; Nagarajan, S.; Benkert, A.; Bär, M.; Blum, M.; Yang, W.; Reinert, F.; Heske, C.; Weinhardt, L.; et al. Ion-Solvation-Induced Molecular Reorganization in Liquid Water Probed by Resonant Inelastic Soft X - Ray Scattering. $J$. Phys. Chem. Lett. 2014, 5, 4143-4148.

Yin, Z.; Rajkovic, I.; Thekku Veedu, S.; Deinert, S.; Raiser, D.; Jain, R.; Fukuzawa, H.; Wada, S.; Quevedo, W.; Kennedy, B.; et al. Ionic Solutions Probed by Resonant Inelastic X-Ray Scattering. Zeitschrift für Phys. Chemie 2015, 229, 1855-1867.

Jeyachandran, Y. L.; Meyer, F.; Benkert, A.; Bär, M.; Blum, M.; Yang, W.; Reinert, F.; Heske, C.; Weinhardt, L.; Zharnikov, M. Investigation of the Ionic Hydration 
in Aqueous Salt Solutions by Soft X-Ray Emission Spectroscopy. J. Phys. Chem. B 2016, $120,7687-7695$.

Petit, T.; Lange, K. M.; Conrad, G.; Yamamoto, K.; Schwanke, C.; Hodeck, K. F.;

Dantz, M.; Brandenburg, T.; Suljoti, E.; Aziz, E. F. Probing Ion-Specific Effects on Aqueous Acetate Solutions: Ion Pairing versus Water Structure Modifications. Struct. Dyn. 2014, 1, 034901,1-8.

Odelius, M. Molecular Dynamics Simulations of Fine Structure in Oxygen KEdge X-Ray Emission Spectra of Liquid Water and Ice. Phys. Rev. B 2009, 79, 144204,16.

Marcus, Y. Effect of Ions on the Structure of Water: Structure Making and Breaking. Chem. Rev. 2009, 109, 1346-1370.

(43) Callahan, K. M.; Casillas-ituarte, N. N.; Roeselova, M.; Allen, H. C.; Tobias, D. J. Solvation of Magnesium Dication : Molecular Dynamics Simulation and Vibrational Spectroscopic Study of Magnesium Chloride in Aqueous Solutions. J. Phys. Chem. A 2010,114 (15), 5141-5148.

(44) Ohtaki, H.; Radnai, T. Structure and Dynamics of Hydrated Ions. Chem. Rev. 1993, 93, 1157-1204.

Gråsjö, J.; Andersson, E.; Forsberg, J.; Aziz, E. F.; Brena, B.; Johansson, C.; Nordgren, J.; Duda, L.; Andersson, J.; Hennies, F.; et al. Electronic Structure of Water Molecules Confined in a Micelle Lattice. J. Phys. Chem. B 2009, 113, 8201-8205.

E.; Weniger, C.; Kalus, C.; Grübel, S.; et al. A Setup for Resonant Inelastic Soft X-Ray Scattering on Liquids at Free Electron Laser Light Sources. Rev. Sci. Instrum. 2012, 83, $123109,1-8$.

Yin, Z.; Peters, H.-B.; Hahn, U.; Gonschior, J.; Mierwaldt, D.; Rajkovic, I.; Viefhaus, J.; Jooss, C.; Techert, S. An Endstation for Resonant Inelastic X-Ray Scattering Studies of Solid and Liquid Samples. J. Synchrotron Radiat. 2017, 24, 302-306.

for Highly Efficient, Load-Balanced, and Scalable Molecular Simulation. J. Chem. Theory Comput. 2008, 4, 435-447.

(49) (1) Ferguson, D. M. Parameterization and Evaluation of a Flexible Water Model. J. Comput. Chem. 1995, 16, 501-511. 
(50) Schuler, L. D.; Daura, X.; Van Gunsteren, W. F. An Improved GROMOS96 Force Field for Aliphatic Hydrocarbons in the Condensed Phase. J. Comput. Chem. 2001, $22,1205-1218$.

(51) Hariharan, P. C.; Pople, J. A. The Influence of Polarization Functions on Molecular Orbital Hydrogenation Energies. Theor. Chim. Acta 1973, 28, 213-222.

(52) Crawford, T. D.; Sherrill, C. D.; Valeev, E. F.; Fermann, J. T.; King; R. A.; Leininger, M. L.; Brown, S. T., Janssen; C. L., Seidl, E. T.; Kenny, J. P. and Allen, W. D. PSI3: An open-source Ab Initio electronic structure package. J. Comput. Chem. 2007, 28, $1610-1616$. 


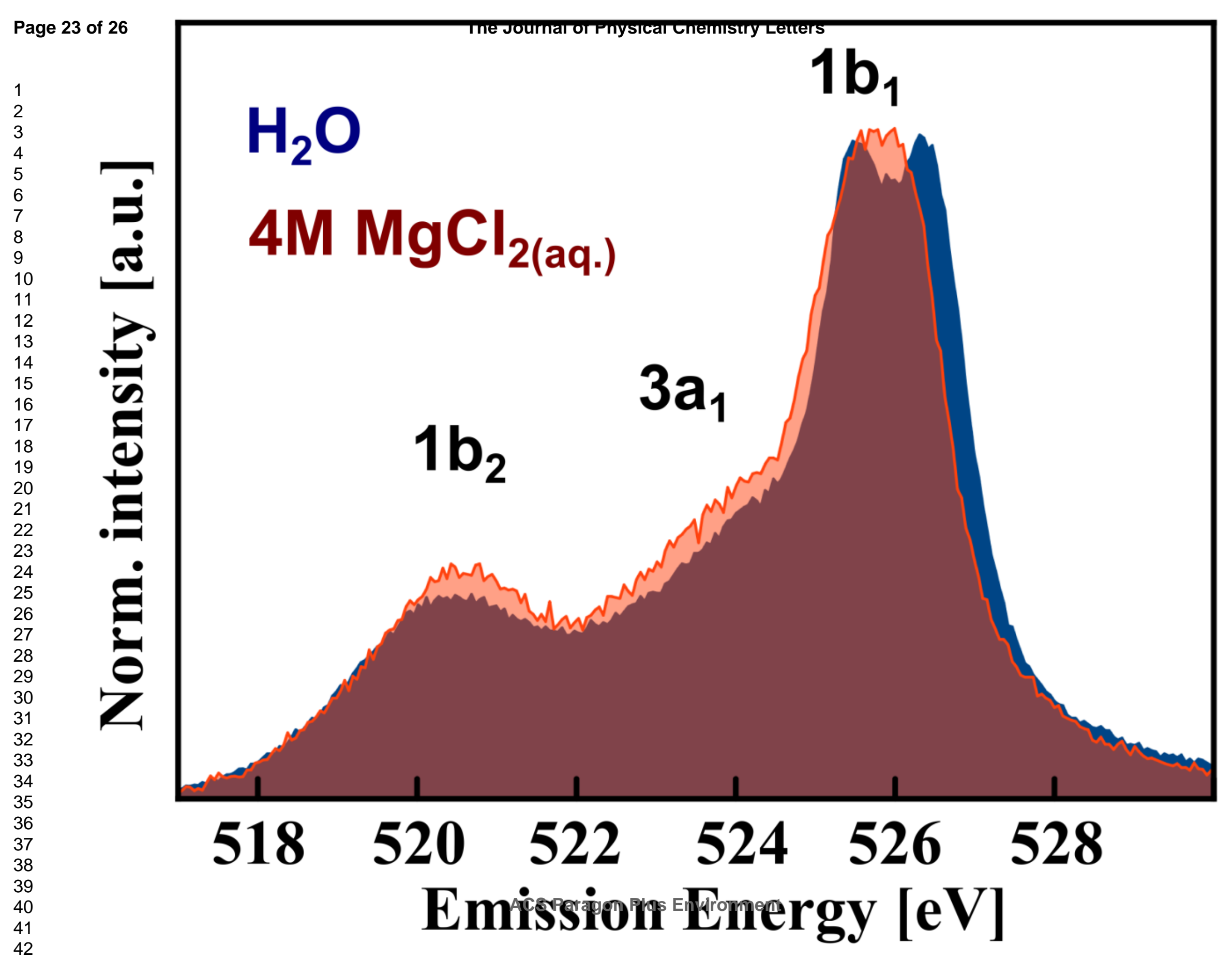




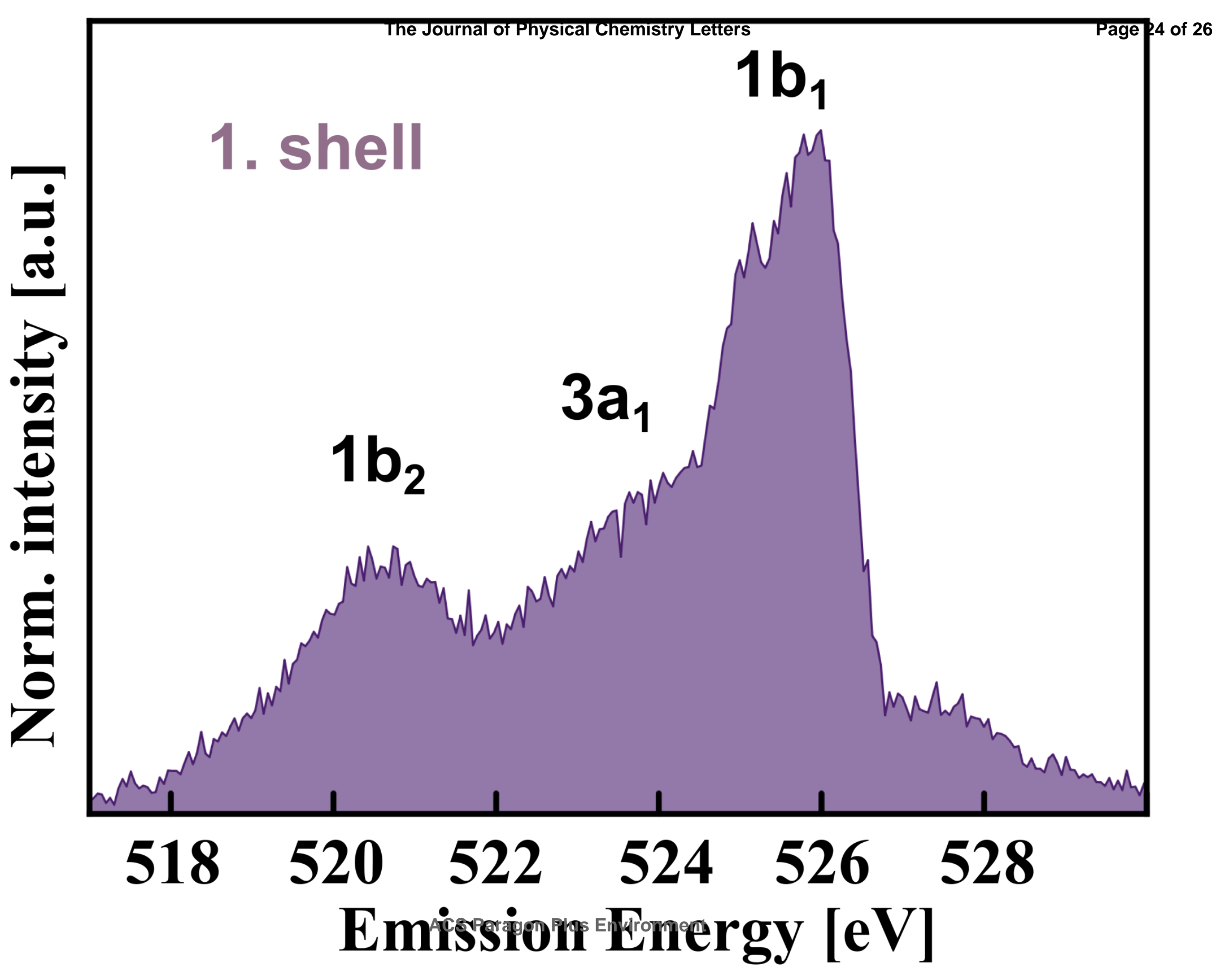




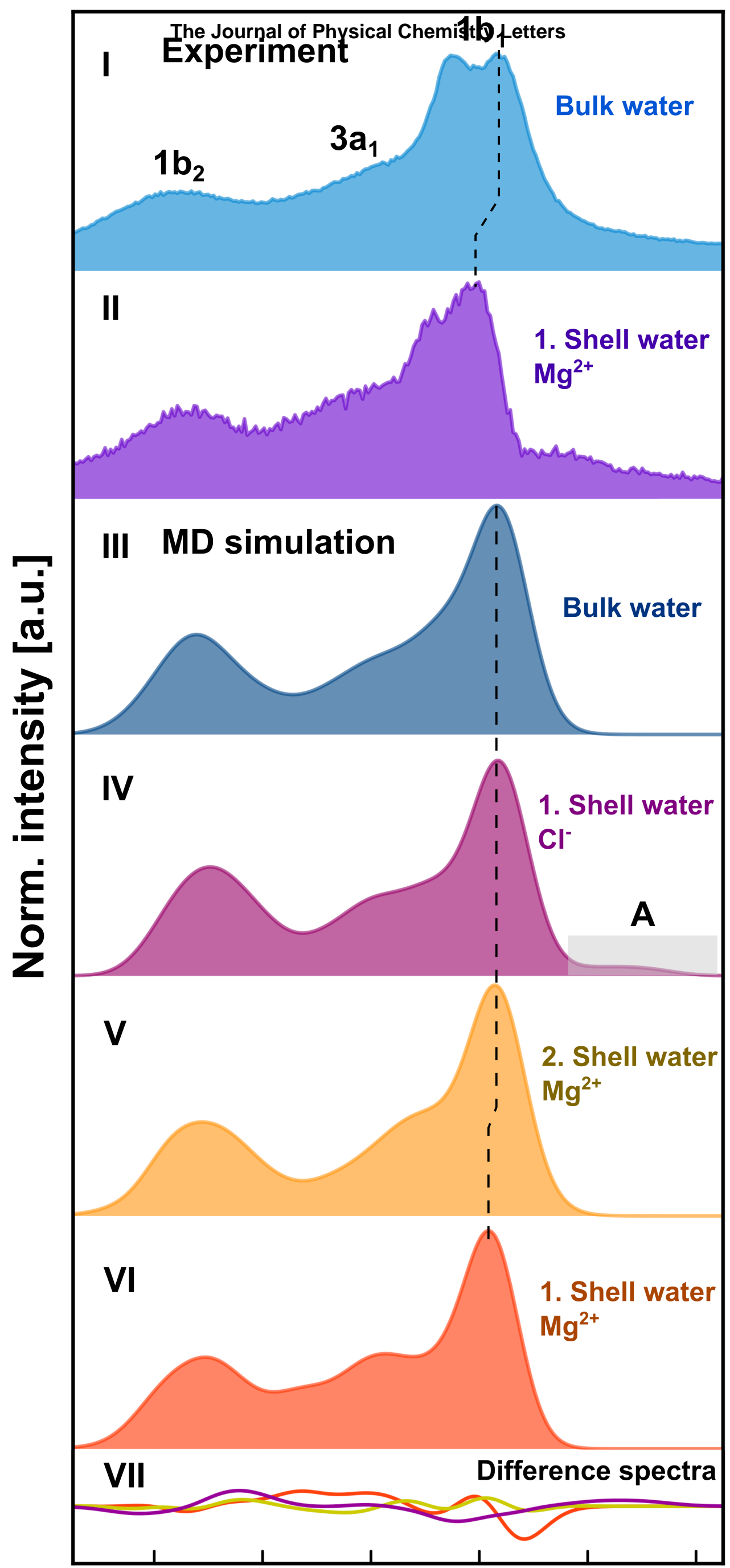

1. Shell water $\mathrm{Mg}^{2+}$

1. Shell water $\mathrm{Cl}^{-}$

2. Shell water $\mathrm{Mg}^{2+}$

1. Shell water $\mathrm{Mg}^{2+}$

520 5222-agon524=nvir526t $528 \quad 530$ Emission Energy [eV] 


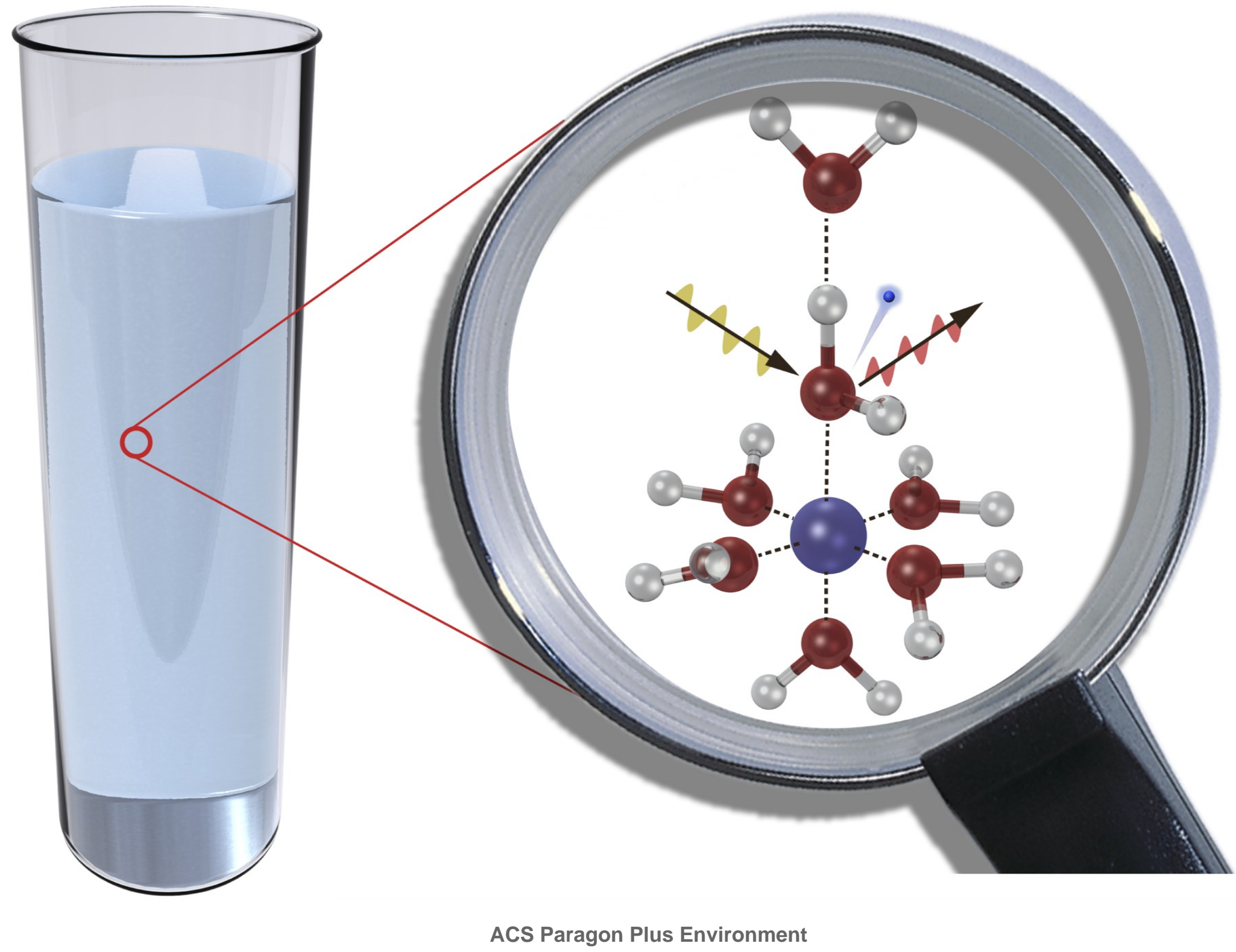

